\title{
Nongenetically transmitted disproportionate ventricular septal thickening associated with left ventricular outflow obstruction
}

\author{
BARRY J. MARON, JOHN S. GOTTDIENER, WILLIAM C. ROBERTS, \\ WILLIAM J. HAMMER, AND STEPHEN E. EPSTEIN
}

From the Cardiology and Pathology Branches, National Heart, Lung, and Blood Institute, National Institutes of Health, Bethesda, Maryland 20014, USA

SUMMARY Clinical, haemodynamic, and morphological features are described in 2 patients with disproportionate ventricular septal thickening, left ventricular outflow obstruction with systolic anterior motion of the anterior mitral leaflet, and either acquired or congenital heart disease. The disproportionate septal thickening in these patients appeared to be secondary to their underlying cardiac disease rather than a manifestation of genetically transmitted hypertrophic cardiomyopathy. One patient with combined aortic and mitral stenosis had severe systolic anterior motion of the anterior mitral leaflet and a residual large systolic pressure gradient between left ventricle and systemic artery after aortic valve replacement. In this patient the systolic anterior motion was evident in the presence of mitral valve stenosis. The other patient with mild aortic stenosis and a previously repaired coarctation of the aorta also had mild systolic anterior motion and a small subaortic systolic pressure gradient. Hence, these 2 patients demonstrate that disproportionate septal thickening secondary to acquired or congenital heart disease may be associated with left ventricular outflow obstruction and systolic anterior motion of the anterior mitral leaflet.

Hypertrophic cardiomyopathy is a disease of cardiac muscle that is characterised by a disproportionately thickened ventricular septum containing numerous disorganised cardiac muscle cells (Teare, 1958; Menges et al., 1961; Abbasi et al., 1972; Ferrans et al., 1972; Abbasi et al., 1973; Clark et al., 1973; Henry et al., 1973; Roberts, 1973; Maron et al., 1974) and is usually transmitted as an autosomal dominant trait (Clark et al., 1973). While the majority of patients with hypertrophic cardiomyopathy have no obstruction to left ventricular outflow (Epstein et al., 1974), others may show dynamic outflow obstruction associated with systolic anterior motion of the anterior mitral leaflet (Shah et al., 1969; Epstein et al., 1974).

Disproportionate septal thickening (Maron et al., 1977a) or clinically evident hypertrophic cardiomyopathy (Parker et al., 1969; Block et al., 1973; Nanda et al., 1974; Bloom et al., 1975; Johnson et al., 1975) may also occur occasionally in patients with acquired or congenital heart diseases. In such patients the septal thickening, rather than a manifestation of genetically transmitted hypertrophic Received for publication 24 July 1978 cardiomyopathy, is probably secondary to the underlying haemodynamic state; obstruction to left ventricular outflow or systolic anterior motion of the anterior mitral leaflet is absent (Maron et al., 1977a).

This report describes the unusual clinical and morphological features in 2 patients with disproportionate septal thickening. In each of these patients left ventricular outflow obstruction and systolic anterior motion of the anterior mitral leaflet was present, but the disproportionate thickening of ventricular septum appeared to be secondary to underlying congenital heart disease in one patient and acquired heart disease in the other patient.

\section{Case 1}

A 67-year-old woman was first seen at the National Heart, Lung, and Blood Institute (NHLBI) because of valvular heart disease. She had a 'strep throat' at age 26 ; a heart murmur was heard shortly thereafter. The patient led an active, normal life until age 60 when she began to experience angina pectoris and lightheadedness. The patient remained stable until 
age 66 when she experienced dyspnoea and fatigue on exertion and orthopnoea. At admission to the NHLBI 7 months later, she was judged to be in functional class III.

On examination, a harsh, grade $4 / 6$ systolic ejection murmer was heard loudest in the second right intercostal space and radiated to the carotids. A high-pitched, grade $3 / 6$ decrescendo diastolic murmer was present along the left sternal border. A grade $2 / 6$ mid-late diastolic rumble was also present at the apex. $S_{2}$ was single. An opening snap was not present. Chest radiograph showed enlargement of the left ventricle and left atrium and normal pulmonary vascular markings. Electrocardiogram showed left ventricular hypertrophy with 'strain' pattern and left atrial enlargement. On echocardiogram, ventricular septal thickness was $22 \mathrm{~mm}$ and posterobasal left ventricular wall thickness was $16 \mathrm{~mm}$. The septal-free wall ratio was $1 \cdot 4$, which met our criteria for disproportionate septal thickening (that is, septal free-wall ratio $\geq 1.3$ ) (Henry et al., 1973; Maron et al., 1977a). Left ventricular transverse dimension in diastole was normal $(38 \mathrm{~mm})$, left atrial transverse dimension was increased $(46 \mathrm{~mm})$, and aortic root diameter was normal $(28 \mathrm{~mm})$. The mitral valve was positioned anteriorly in the left ventricular cavity, as evidenced by an abnormal mitral valve position index of 1.7 (normal, < 0.3) (Henry et al., 1975). The mitral valve leaflets were not imaged adequately to judge the presence or absence of systolic anterior motion of the anterior mitral leaflet.

Haemodynamic data from the patient's two cardiac catheterisations are summarised in the Table. At the initial catheterisation (age 66; 8 October 1974) the patient showed a pronounced peak systolic pressure gradient of $80 \mathrm{mmHg}$ across the aortic valve and a critically reduced aortic valve index $\left(0.2 \mathrm{~cm}^{2} / \mathrm{m}^{2}\right)$. A small $5 \mathrm{mmHg}$ mean diastolic gradient was present across the mitral valve and the mitral valve index was $1.8 \mathrm{~cm}^{2} / \mathrm{m}^{2}$. Left ventriculography showed normal ventricular wall motion and no mitral regurgitation; ejection fraction was $0 \cdot 80$. Because of the patient's clinical and haemodynamic findings, aortic valve replacement was performed one week later. At operation, the aortic valve was tricuspid, severely stenotic, and calcified. A no. 19 Björk-Shiley prosthesis was inserted. The mitral leaflets, examined via the left atrium, were thickened, mobile, and free of calcium. The orifice had a diameter of about $4 \mathrm{~cm}$.

Over the next 7 months the patient continued to experience exertional dyspnoea and fatigue. A second cardiac catheterisation (aged 67; 12 May 1975) was performed and showed a persistent $80 \mathrm{mmHg}$ gradient between the left ventricle and femoral artery. In addition, there was evidence of increased mitral stenosis; the mitral valve gradient was $15 \mathrm{mmHg}$ and the mitral valve index $0.8 \mathrm{~cm}^{2}$ / $\mathrm{m}^{2}$ (Table). At this time, echocardiography indicated distinct systolic anterior motion of the anterior mitral leaflet, with prolonged contact between the anterior mitral leaflet and ventricular septum(Fig.1). Because of the patient's persistent symptoms, evidence of residual left ventricular outflow tract obstruction, increasing mitral valve gradient, and diminished valve area, it was thought that she would benefit from mitral valve replacement. Hence, a no. 25 Björk-Shiley prosthesis was inserted on 15 May 1975. The excised mitral valve was diffusely fibrotic, non-calcified, and showed fused commissures. Immediately after operation a maximum peak systolic gradient of $25 \mathrm{mmHg}$ was recorded between left ventricle and aorta in the

Table Haemodynamic data

\begin{tabular}{|c|c|c|c|c|c|c|}
\hline \multirow[b]{2}{*}{ Date } & \multicolumn{5}{|l|}{ Case 1} & \multirow[t]{2}{*}{ Case 2} \\
\hline & $8 / 10 / 74$ & $16 / 10 / 74$ & $12 / 5 / 75$ & $15 / 5 / 75$ & $23 / 5 / 75$ & \\
\hline \multicolumn{7}{|l|}{ Pressures (mmHg) } \\
\hline Right ventricle & $45 / 3$ & $\begin{array}{l}\text { Aortic valve } \\
\text { replacement }\end{array}$ & $40 / 6$ & $\begin{array}{l}\text { Mitral valve } \\
\text { replacement }\end{array}$ & Death & $26 / 10$ \\
\hline Pulmonary artery & $45 / 20(25)$ & & $40 / 20(28)$ & & & $32 / 15(22)$ \\
\hline Pulmonary capillary wedge & 17 & & 20 & & & 13 \\
\hline Left ventricle & $240 / 14$ & & $240 / 18$ & & & $185 / 22$ \\
\hline Systemic artery & $160 / 50$ & & $160 / 75$ & & & $125 / 65$ \\
\hline Left ventricular peak systolic gradient & $80 \star$ & & $80 t$ & & & $60 \ddagger$ \\
\hline \multicolumn{7}{|l|}{ Indices } \\
\hline Aortic valve index $\left(\mathrm{cm}^{2} / \mathrm{m}^{2}\right)$ & $0 \cdot 2$ & & - & & & - \\
\hline Mitral valve index $\left(\mathrm{cm}^{2} / \mathrm{m}^{2}\right)$ & $1 \cdot 8$ & & 0.8 & & & $\overline{-}$ \\
\hline Cardiac index $\left(1 / \min\right.$ per $\left.\mathrm{m}^{2}\right)$ & $2 \cdot 3$ & & $2 \cdot 2$ & & & $3 \cdot 4$ \\
\hline
\end{tabular}

Symbols:

*Across aortic valve as shown by pullback pressure recording from left ventricle to aorta.

- = Data not available.

tObtained by simultaneous recording from left ventricle and femoral artery.

$\$ 30 \mathrm{mmHg}$ aortic valvular gradient and $30 \mathrm{mmHg}$ subaortic gradient. 


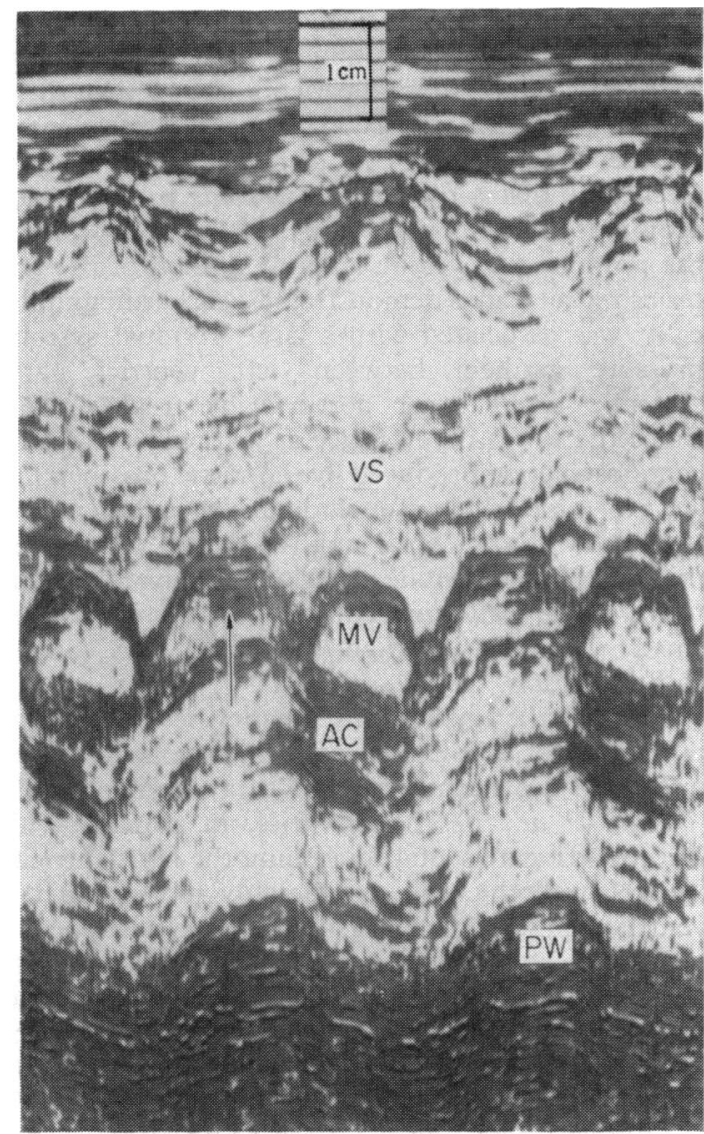

Fig. 1 Echocardiogram recorded in case 1 under basal conditions 7 months after aortic valve replacement, when a residual $80 \mathrm{mmHg}$ gradient was present between the left ventricle and femoral artery. Distinct systolic anterior motion of the anterior mitral leaflet is shown (arrow). $M V$, mitral valve; VS, ventricular septum; $P W$, posterobasal left ventricular free wall; $A C$, mitral annular calcification.

operating room. Postoperatively she had a low output state with shock and impaired renal function, and died 8 days after operation.

At necropsy the heart was increased in weight $(500 \mathrm{~g})$. All 4 cardiac chambers were normal in size. Maximal ventricular septal thickness was $24 \mathrm{~mm}$, posterobasal left ventricular wall thickness was $21 \mathrm{~mm}$, and septal-free wall ratio was $1 \cdot 1$. There was no endocardial contact plaque on the ventricular septum. The mitral annulus was heavily calcified. Both the aortic and mitral prostheses were free of thrombus and the poppets moved freely. The coronary arteries were free of significant luminal narrowing.
Histological examination of the ventricular septal and left ventricular free wall myocardium showed the vast majority of cardiac muscle cells to be in normal parallel alignment. Small foci of disorganised cardiac muscle cells (Teare, 1958; Ferrans et al., 1972; Maron et al., 1974) were present in the vencular septum (totalling only $0.7 \%$ of the area occupied by cells cut longitudinally) and were more limited in extent than those usually found in patients with hypertrophic cardiomyopathy (Maron et al., 1978). Echocardiographic studies performed in the patient's three first degree relatives ( 2 sons and a sister) revealed a normal septal-free wall ratio in each.

\section{Case 2}

A 40-year-old woman was first recognised as having coarctation of the aorta as an adolescent. This malformation was repaired at age 21 . The patient was in good health until age 39 when she noted exertional dyspnoea, fatigue, occasional paroxysmal nocturnal dyspnoea, and angina pectoris. When admitted to hospital, she was in functional class II to III. On examination, she had a grade $3 / 6$ systolic ejection murmer along the left sternal border which increased with the Valsalva manoeuvre and diminished with squatting. Systemic blood pressure was $135 / 90 \mathrm{mmHg}$. Electrocardiogram showed flattened $\mathrm{T}$ waves in leads III, aVF, and V4 to V6. Chest radiograph showed normal heart size (cardiothoracic ratio $=0.47$ ). On the echocardiogram ventricular septal thickness was $18 \mathrm{~mm}$, posterobasal left ventricular free wall thickness was $10 \mathrm{~mm}$, and septal-free ratio was 1.8 (Fig. 2). Left ventricular transverse internal dimension in diastole was normal $(51 \mathrm{~mm})$, left atrial transverse dimension was slightly increased $(43 \mathrm{~mm})$, and aortic root diameter was normal $(26 \mathrm{~mm})$. The mitral valve was positioned anteriorly in the left ventricular cavity, as evidenced by a mitral valve position index of $0 \cdot 6$ (Henry et al., 1975). Mild systolic anterior motion of the anterior mitral leaflet was present. Echocardiographic studies were also performed in the patient's 7 first degree relatives (2 sibs and 5 offspring); normal septal-free wall ratio was present in each.

Haemodynamic data from the patient's cardiac catheterisation are summarised in the Table. A peak systolic pressure gradient of $30 \mathrm{mmHg}$ was present across the aortic valve and an additional $30 \mathrm{mmHg}$ gradient was present across the left ventricular outflow tract below the valve; with isoprenaline infusion the overall gradient increased to $85 \mathrm{mmHg}$. Left ventricular angiography showed obvious cavity obliteration in end-systole and a mildly thickened aortic valve; no mitral regurgitation was present. Coronary arteriography showed normal arteries. 


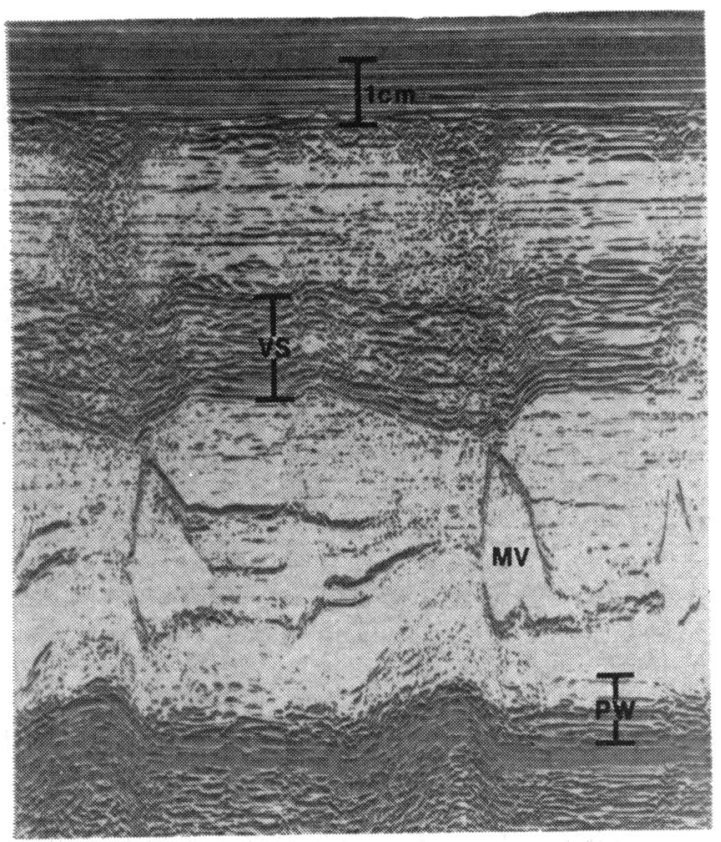

Fig. 2 Echocardiogram recorded in case 2 showing disproportionate thickening of the ventricular septum $(V S)$ with respect to the posterobasal left ventricular free wall $(P W)$. At a level inferior to that shown here, ventricular septal thickness was slightly greater $(18 \mathrm{~mm})$ but posterobasal left ventricular free wall thickness was not significantly different. This study was obtained at a time when the patient was taking propranolol and, hence, systolic anterior motion of the anterior mitral valve was not present.

\section{Discussion}

Disproportionate septal thickening present in the 2 patients reported here appeared to be secondary to underlying cardiac diseases (Maron et al., 1977a) rather than to genetically transmitted hypertrophic cardiomyopathy. This conclusion was suggested by the following evidence: (1) echocardiographic studies in 10 first degree relatives of both patients showed normal septal-free wall ratios; and (2) the arrangement of cardiac muscle cells in ventricular septal myocardium obtained at necropsy from case 1 was not typical of hypertrophic cardiomyopathy (Teare, 1958; Ferrans et al., 1972; Maron et al., 1974,1978 ), that is, numerous disorganised cardiac muscle cells were not present. It is probable that disproportionate septal thickening was secondary to the haemodynamic consequences of severe aortic and mitral valvular stenosis in case 1 and of coarctation of the aorta (repaired at age 21) and mild aortic valvular stenosis in case 2 .
Hence, the left ventricular outflow obstruction and systolic anterior motion of the anterior mitral leaflet present in our 2 patients shows that these abnormalities may occasionally be associated with the secondary form of disproportionate septal thickening that can be found in some patients with acquired or congenital heart disease. In case 1 the pronounced systolic anterior motion of the anterior mitral leaflet demonstrated echocardiographically was associated with a large residual systolic pressure gradient between left ventricle and systemic artery after aortic valve replacement. Since there was no evidence at necropsy of significant obstruction produced by the aortic prosthesis, it appears reasonable to conclude that the gradient was caused by mitral-septal apposition. In case 2 the mild degree of systolic anterior motion of the anterior mitral leaflet present was consistent with the small subaortic gradient recorded at cardiac catheterisation.

In case 1 the apparent discrepancy between necropsy and echocardiographic assessments of septal-free wall ratio has been explained in a previous study (Maron et al., 1977b). In brief, in patients with disproportionate septal thickening the left ventricular free wall thickens considerably more than the ventricular septum in systole. Since postmortem hearts are often fixed in the systolic phase of the cardiac cycle, septal-free wall ratios obtained at necropsy, or in systole by echocardiography, are usually smaller than ratios obtained in diastole by echocardiography (as per convention).

Another interesting point regarding case 1 is that systolic anterior motion of the anterior mitral leaflet occurred despite the presence of organic mitral stenosis. The ability of the mitral valve to move into the left ventricular outflow tract and abut against the ventricular septum during systole can probably only occur in patients with mitral stenosis in which the mitral valve leaflets are not calcified and manifest a considerable degree of mobility.

\section{References}

Abbasi, A. S., MacAlpin, R. N., Eber, L. M., and Pearce, M. L. (1972). Echocardiographic diagnosis of idiopathic hypertrophic cardiomyopathy without outflow obstruction. Circulation, 46, 897-904.

Abbasi, A. S., MacAlpin, R. N., Eber, L. M., and Pearce, M. L. (1973). Left ventricular hypertrophy diagnosed by echocardiography. New England fournal of Medicine, 289, 118-121.

Block, P. C., Powell, W. J., Jr., Dinsmore, R. E., and Goldblatt, A. (1973). Coexistent fixed congenital and idiopathic hypertrophic suboartic stenosis. American fournal of Cardiology, 31, 523-526.

Bloom, K. R., Meyer, R. A., Bove, K. E., and Kaplan, S. (1975). The association of fixed and dynamic left ventricularoutflow obstruction. American Heart fournal, 89, 586-590. 
Clark, C. E., Henry, W. L., and Epstein, S. E. (1973). Familial prevalence and genetic transmission of idiopathic hypertrophic subaortic stenosis. New England fournal of Medicine, 289, 709-714.

Epstein, S. E., Henry, W. L., Clark, C. E., Roberts, W. C., Maron, B. J., Ferrans, V. J., Redwood, D. R., and Morrow, A. G. (1974). Asymmetric septal hypertrophy. Annals of Internal Medicine, 81, 650-680.

Ferrans, V. J., Morrow, A. G., and Roberts, W. C. (1972). Myocardial ultrastructure in idiopathic hypertrophic subaortic stenosis. A study of operatively excised left ventricular outflow tract muscle in 14 patients. Circulation, 45, 769-792.

Henry, W. L., Clark, C. E., and Epstein, S. E. (1973). Asymmetric septal hypertrophy: echocardiographic identification of the pathognomonic anatomic abnormality of IHSS. Circulation, 47, 225-233.

Henry, W. L., Clark, C. E., Griffith, J. M., and Epstein, S. E. (1975). Mechanism of left ventricular outflow obstruction in patients with obstructive asymmetric septal hypertrophy (idiopathic hypertrophic subaortic stenosis). American fournal of Cardiology, 35, 337-345.

Johnson, A. D., Lonky, S. A., and Carleton, R. A. (1975). Combined hypertrophic subaortic stenosis and calcific aortic valvular stenosis. American fournal of Cardiology, 35, 706-709.

Maron, B. J., Clark, C. E., Henry, W. L., Fukuda, T., Edwards, J. E., Mathews, E. C., Jr., Redwood, D. R., and Epstein, S. E. (1977a). Prevalence and characteristics of disproportionate ventricular septal thickening in patients with acquired or congenital heart disease: echocardiographic and morphologic findings. Circulation, 55, 489-496.

Maron, B. J., Epstein, S. E., and Roberts, W. C. (1978). Cardiac muscle cell disorganisation in the ventricular septum: evidence from quantitative histology that it is a highly sensitive marker of hypertrophic cardiomyopathy (abstract). American fournal of Cardiology, 41, 435.

Maron, B. J., Ferarns, V. J., Henry, W. L., Clark, C. E.,
Redwood, D. R., Roberts, W. C., Morrow, A. G., and Epstein, S. E. (1974). Differences in distribution of myocardial abnormalities in patients with obstructive and nonobstructive asymmetric septal hypertrophy (ASH): light and electron microscopic findings. Circulation, 50, 436-446.

Maron, B. J., Henry, W. L., Roberts, W. C., and Epstein, S. E. (1977b). Comparison of echocardiographic and necropsy measurements of ventricular wall thicknesses in patients with and without disproportionate septal thickening. Circulation, 55, 341-346.

Menges, H., Brandenburg, R. O., and Brown, A. L. (1961). The clinical, hemodynamic and pathologic diagnosis of muscular subvalvular aortic stenosis. Circulation, 24, 1126-1136.

Nanda, N. C., Gramiak, R., Shah, P. M., Stewart, S., and DeWeese, J. A. (1974). Echocardiography in the diagnosis of idiopathic hypertrophic subaortic stenosis co-existing with aortic valve disease. Circulation, 50, 752-757.

Parker, D. P., Kaplan, M. A., and Connolly, J. E. (1969). Coexistent aortic valvular and functional hypertrophic subaortic stenosis. Clinical, physiologic and angiographic aspects. American fournal of Cardiology, 24, 307-317.

Roberts, W. C. (1973). Valvular, subvalvular and supravalvular aortic stenosis: morphologic features. Cardiovascular Clinics, 5, 97-126.

Shah, P. M., Gramiak, R., and Kramer, D. H. (1969). Ultrasound localization of left ventricular outflow obstruction in hypertrophic obstructive cardiomyopathy. Circulation, 40, 3-11.

Teare, D. (1958). Asymmetrical hypertrophy of the heart in young patients. British Heart fournal, 20, 1-8.

Requests for reprints to Dr Barry J. Maron, Cardiology Branch, National Institute of Health, Building 10, Room 7B-15, Bethesda, Maryland 20014, USA. 